\title{
VoWiFi - Avaliação de VoIP Utilizando Weibull para Emulação do Canal.
}

\author{
Alessandra Bussolin Bandeira, Fernando Lino, Omar Carvalho Branquinho, Norma Reggiani
}

\begin{abstract}
Resumo-O artigo avalia de forma quantitativa e qualitativa o desempenho de VoIP em rede WLAN, denominado WVoIP. Foi utilizado um emulador de canal para criar o cenário de degradação provocado pela mobilidade. Foram avaliados dois codificadores de voz: G711 e GSM. Resultados indicam o efeito dos fenômenos de instabilidade da rede sem fio em variações na qualidade de voz em função da intensidade dos fenômenos emulados. Foram analisadas as questões relativas aos CODECs que possuem características de banda e robustez diferentes.
\end{abstract}

Palavras-Chave-VoIP, WVoIP, Wlan, Weibull, Codec

Abstract-This article evaluates in a quantitative and qualitative way the performance of VoIP through a WLAN network, what is called WVoIP. A channel emulator is used to create the scenario of degradation done by the mobility. Two types of encoders had been evaluated: G711 and GSM. The results show the effect of the wireless network instability over quality of the voice in function of the simulated phenomenon. Relative questions to the CODECs are analyzed which has owns characteristics about band and robustness.

\section{Index Terms-VoIP, WVoIP, Wlan, Weibull, Codec}

\section{INTRODUÇÃO}

Voz sobre IP (VoIP) é uma aplicação que vem crescendo muito na Internet, pois oferece economia principalmente nas ligações para longa distância. Paralelamente, temos o crescimento das redes sem fio, através das WLANs (Wireless Local Área Network) que proporcionam a mobilidade e banda larga em locais públicos. Em [1], aborda-se a evolução das redes móveis, e a convergência dessas duas tecnologias, sendo a principal vantagem o aproveitamento de banda de freqüência não licenciada.

Pontifícia Universidade Católica de Campinas, Brasil, E-mails: Alessandra Bussolin Bandeira ale@puc-campinas.edu.br, Fernando Lino flino@alcatel$\underline{\text { lucent.com, Omar de C. Branquinho branquinho@puc-campinas.edu.br, }}$ Norma Reggiani nreggiani@puc-campinas.edu.br.
Verifica-se que a tendência das redes sem fio é se tornarem independentes das redes cabeadas criando redes para serviço em ambiente público denominada PWLAN (Public Wireless $L A N$ ). Esta aplicação é suportada pelo protocolo IP (Internet Protocol), que cria condições de atender à integração de serviços e aplicações entre estas redes e os dispositivos móveis existentes [2].

A combinação da disseminação das redes que comportam o protocolo IP pelo mundo, da necessidade de transporte desse tráfego de dados em tempo real, da mobilidade oferecida pela WLAN (padrão 802.11), aliados a convergência das redes, impulsionou nos últimos anos estudos para analisar a condição de QoS (Quality of Service), ou seja, do VoWiFi (VoIP over Wifi), enfatizando a importância desse tema.

Existem alguns desafios a serem superados e que comprometem o desempenho da tecnologia: a ineficiência da MAC (Medium Access Control) do padrão 802.11; o desempenho inaceitável quando a aplicação de voz coexiste com outras aplicações de dados, como por exemplo, serviços de web , e-mail e ftp [3] e os diversos fenômenos que podem degradar significativamente a qualidade do sinal e a eficiência da rede. Dentre os problemas citados, o trabalho está focado na instabilidade de sinal dessas redes na sua componente fast fading, correlacionados à qualidade de voz. É investigado o desempenho de dois codificadores de voz (codec) que apresentam características de banda e robustez diferentes.

O trabalho está organizado da seguinte forma: no Item II são tratados os fatores de interferência na qualidade VoIP. No Item III são apresentadas as principais medidas de qualidade da voz. No Item IV é apresentada a metodologia e o ambiente de teste. No Item V são apresentados os resultados obtidos. Por fim, o Item VI contém a conclusão do trabalho.

\section{FATORES DE QUALIDADE VOIP}

Para uma comunicação utilizando-se voz sobre IP, existem alguns fatores que determinam a boa inteligibilidade da comunicação, entre a codificação e decodificação do sinal. Os fatores mais significativos que contribuem para a degradação da qualidade de voz, em uma rede comutada por pacotes, que são perceptíveis aos usuários e estão relacionados diretamente com a rede de comunicação são:

1) Perda de pacotes: A perda de pacotes é um fator que influencia diretamente na qualidade da voz. Dentre os fatores 
que levam a perda de pacotes IP, estão à largura de banda, instabilidades de rota da rede e estouro do buffer de recepção nos routers e switches.

2) Jitter: A variação de atraso (jitter) é um fenômeno que ocorre em virtude do atraso variável da transmissão dos pacotes de voz, que chegam ao destino não preservando a seqüência original. O jitter pode resultar em intervalos de silêncio dentro de um surto de voz, diminuir, ou até mesmo eliminar esses intervalos, o que pode causar a perda da integibilidade da informação no destino. [4]

3) Atraso fim a fim: O retardo de transferência máxima, introduzida pela rede de comunicação é um fator crítico para aplicações que exigem comunicação em tempo real.

A Tabela I relaciona os parâmetros em questão com a qualidade de conversação.

Tabela I: Correlação dos parâmetros com a qualidade da conversação [5].

\begin{tabular}{|c|c|c|c|}
\hline $\begin{array}{c}\text { Categorias de } \\
\text { Qualidade da } \\
\text { Voz }\end{array}$ & $\begin{array}{c}\text { Atraso fim-a- } \\
\text { fim }\end{array}$ & $\begin{array}{c}\text { Média das } \\
\text { perdas de } \\
\text { pacotes }\end{array}$ & $\begin{array}{c}\text { Variação } \\
\text { do atraso }\end{array}$ \\
\hline Perfeito & $<150 \mathrm{~ms}$ & $00 \%$ & $0 \mathrm{~ms}$ \\
\hline Bom & $<250 \mathrm{~ms}$ & $03 \%$ & $75 \mathrm{~ms}$ \\
\hline Médio & $<350 \mathrm{~ms}$ & $15 \%$ & $125 \mathrm{~ms}$ \\
\hline Ruim & $<450 \mathrm{~ms}$ & $25 \%$ & $225 \mathrm{~ms}$ \\
\hline
\end{tabular}

Quando o fator responsável pela degradação da voz está relacionado à rede de transporte, a escolha do codec será uma questão a ser observada, principalmente se o canal apresentar alto grau de instabilidade.

O codificador de voz é responsável pela representação do sinal analógico em digital, de forma que seja utilizado um número reduzido de bits para o armazenamento e transmissão desse sinal.

A maioria dos codificadores de voz se baseiam em quadros, comprimindo um número fixo de amostras em blocos. Para diminuir esse atraso, o codificador deve ter um comprimento de quadro pequeno, porém verifica-se que quanto maior o quadro, maior será sua eficiência, na medida em que serão transmitidos mais quadros por pacote, e conseqüentemente uma maior carga útil (payload), diminuindo o efeito da banda consumida pelos cabeçalhos dos protocolos envolvidos nessa comunicação (RTP/UDP/IP) [5]. Entretanto grande carga útil em canal instável pode representar perda da eficiência e degradação da qualidade.

O trabalho analisa o desempenho de dois codecs: G.711 PCM (Companded Pulse Code Modulation) e GSM, a Tabela II contém informações quanto à estrutura e qualidade de voz para diferentes codificadores.
Tabela II. Estrutura e qualidade de voz para diferentes tipos de codificadores. [5]

\begin{tabular}{|c|c|c|c|c|}
\hline Padrão & $\begin{array}{c}\text { Taxa de } \\
\text { Compressão } \\
\text { (kbit/s })\end{array}$ & $\begin{array}{c}\text { Quadro } \\
\text { (ms) }\end{array}$ & $\begin{array}{c}\text { Payload } \\
\text { (Bytes) }\end{array}$ & $\begin{array}{c}\text { Qualidade } \\
\text { da voz }\end{array}$ \\
\hline G.711 & 64 & 20 & 160 & Boa \\
\hline G.726 & 32 & 20 & 80 & Boa \\
\hline G.729 & 8 & 10 & 10 & Boa \\
\hline GSM & 13.2 & 20 & 33 & Média \\
\hline
\end{tabular}

\section{MEdIDAs DE QUALIDADE VoIP}

Verifica-se que as expectativas das pessoas que utilizam serviço VoIP são baseadas em experiências adquiridas no uso habitual da telefonia convencional, e através dessa expectativa subjetiva, surgem testes para medir a qualidade de voz.

Algumas recomendações para a medida de qualidade subjetiva da voz foram especificadas por órgãos de padronização. O ITU-T (International telecomunication Union - Telecomunication) especificou a Recomendação P.800 [6], que define o método MOS (Mean Opinion ScoreÍndice de Opinião Médio). As medidas são derivadas de várias amostras de voz pré-selecionadas sobre meios de transmissão diferentes, reproduzidas em condições controladas, para um grupo de pessoas que fazem o julgamento da qualidade de voz de acordo com uma escala de 1 a 5 .

Testes subjetivos exigem recursos humanos e gastam mais tempo, além disso, não são capazes de medir aspectos, tais como, jitter e perda de pacotes, que são dados relevantes. Por isso, muitos esforços estão sendo feitos para desenvolver modelos que façam a avaliação da qualidade de voz através de parâmetros objetivos. Dentre esses modelos, há o modelo$E$ [7] que mede a qualidade fim a fim, calculando um fator $R$ onde é considerado todos os fatores que interferem na comunicação. A Expressão 1 apresenta a expressão geral do fator R.

$$
R=R o-I s-I d-I e+A
$$

Onde:

Ro $=$ Ruído

Is $=$ Fatores de interferências.

Id = interferências por atrasos

$\mathrm{Ie}=$ Interferências por equipamentos

A = Fator da especificação

A Recomendação G.109 [8] apresenta uma correspondência entre o valor R (teste objetivo) e o valor de MOS (teste subjetivo) conforme a Tabela III. 
Tabela III. Valores de correspondência entre o Fator R e o MOS [7]

\begin{tabular}{|c|c|c|}
\hline Fator-R & MOS & $\begin{array}{c}\text { Satisfação do } \\
\text { usuário }\end{array}$ \\
\hline 90 & 4.34 & Muito satisfeito \\
\hline 80 & 4.03 & Satisfeito \\
\hline 70 & 3.60 & $\begin{array}{c}\text { Alguns usuários } \\
\text { insatisfeitos }\end{array}$ \\
\hline 60 & 3.10 & $\begin{array}{c}\text { Muitos usuários } \\
\text { insatisfeitos }\end{array}$ \\
\hline 50 & 2.58 & $\begin{array}{c}\text { Quase todos } \\
\text { usuários insatisfeitos }\end{array}$ \\
\hline
\end{tabular}

\section{MEtodologia}

Nos últimos anos, as redes sem fio baseadas no padrão IEEE 802.11 vêm ganhando popularidade, e sendo utilizadas na comunicação entre diversos dispositivos em diferentes ambientes. Porém verifica-se que o desempenho do VoWiFi é comprometido por diversos fenômenos que podem degradar significativamente a qualidade do sinal e a eficiência da rede, podendo conseqüentemente degradar a qualidade de comunicação da voz, que trafega sobre esse sistema.

O sinal que chega ao receptor de uma comunicação sem fio é formado pela composição de sinais vindos de diversas direções e de diferentes caminhos (multipath) que podem apresentar instabilidade pelos fenômenos reflexão, difração e/ou dispersão. [9] Tais fenômenos resultam em variações aleatórias da intensidade do sinal (fading) que chega ao receptor com atraso e diferentes componentes de amplitude e fase. Modelos estatísticos são utilizados para representar os fenômenos que ocorrem em uma rede 802.11, sendo as distribuições de Rayleigh e Ricean as mais utilizadas. [10] Entretanto, estas distribuições são mais utilizadas para representar ambiente outdoor.

Para avaliação de VoWiFi é utilizada distribuição mais geral, que é a distribuição de Weibull que apresenta dois graus de liberdade: fator de forma e fator de escala. Esta distribuição é dada por:

$$
f(x)=\alpha \beta^{-\alpha} \cdot x^{\alpha-1} e^{-\left(\frac{x}{\beta}\right)^{\alpha}} \text { para } x>0
$$

onde $\alpha$ é o fator de forma e $\beta$ é o fator de escala

Para $\alpha=2$ temos um caso particular da distribuição de Weibull que é a distribuição Rayleigh. A escolha desta distribuição é resultado de uma pesquisa que avalia o comportamento do fast fading em ambientes indoor.

Medidas realizadas em diversos ambientes utilizando um robô mostram a variação do fator $\beta$ como mostrado na Figuras 1 e 2 e ilustram a Função Densidade Probabilidade e a Função Distribuição.
Podemos observar a variação do desvio padrão de função densidade de probabilidade em função dos valores distintos de $\beta$.

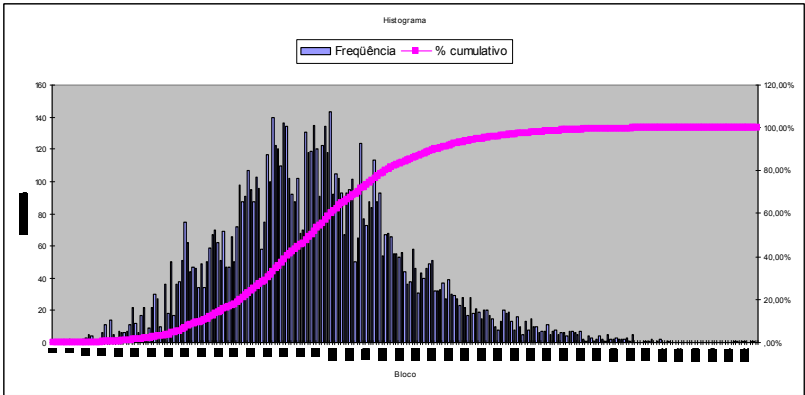

Fig.1. Distribuição de Weibull para $\alpha=2$. e $\beta=1,26$

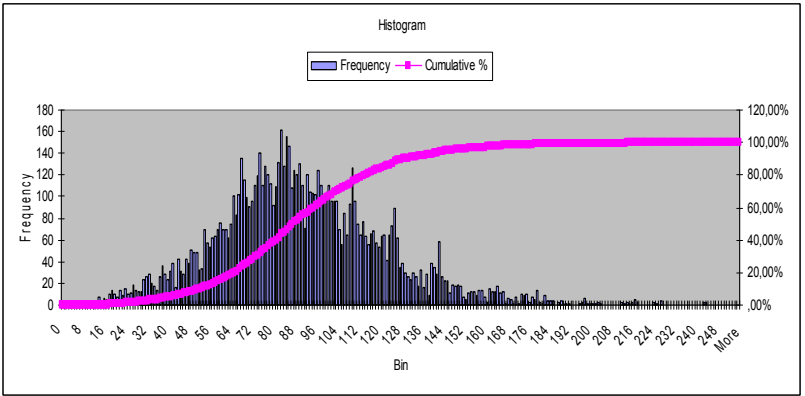

Fig.2. Distribuição de Weibull para $\alpha=2$ e $\beta=1,34$

A Figura 3 mostra o robô que capturou as medidas de intensidade de sinal confirmando que a distribuição Weibull atende às variações encontradas em ambiente indoor.

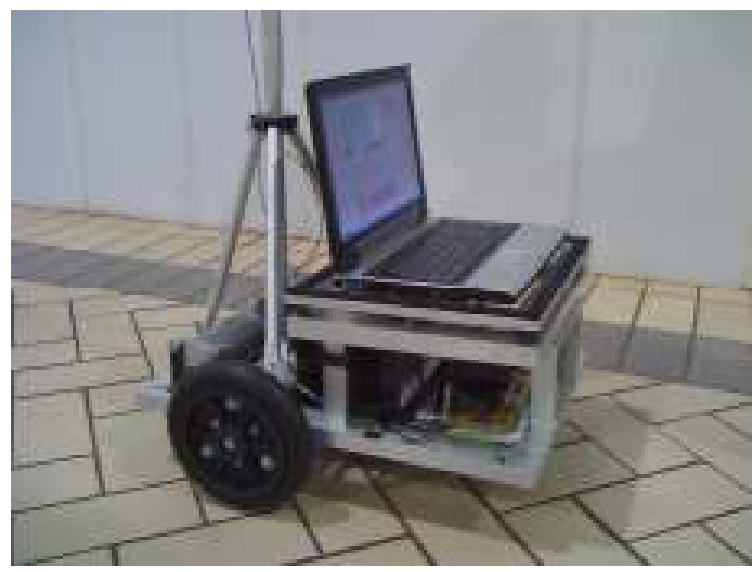

Fig. 3. Robô utilizado durante os testes.

O intervalo de medidas feitas pelo robô foi determinado por:

$$
\lambda=\frac{v}{f}
$$

Para uma rede $802.11 \mathrm{~b}$ temos um comprimento de onda de $12,5[\mathrm{~cm}]$. 
Considerando que o intervalo entre dois valores de potência medidos para a distância de meio comprimento de onda seja de 0,0625 [m] e considerando uma pessoa se movendo a uma velocidade de $1 \mathrm{~m} / \mathrm{s}$, num intervalo de um comprimento de onda, o período entre medições seria:

$$
\Delta \mathrm{s}=v \cdot t
$$

Obtendo um valor de $\mathrm{t}=125[\mathrm{~ms}]$

As medidas de potência realizadas pelo robô foram efetuadas em intervalos de 200 [ms].

\section{EMULAÇÃO DE CANAL}

Para emulação de canal foram utilizadas as medidas obtidas pelo robô, sendo modificada a severidade do ambiente através do valor de $\beta$. O fator $\alpha$ também pode ser variado criando mais um grau de liberdade, porém em nosso trabalho é utilizado $\alpha=2$, o que representa uma distribuição de Rayleigh. $\mathrm{O}$ ajuste de $\beta$ e $\alpha$ permite a caracterização do ambiente.

É emulado um canal fast flat fading através de uma bancada, que reproduz um usuário com uma chamada VoIP estendida em movimento, tendo ambientes com níveis de obstrução entre transmissor e receptor móvel variando.

Conforme a Figura 4, determinados valores de tensão são encaminhados para um bloco de controle que é responsável pela conversão digital/analógico e pelo ajuste de ganho e do Off-set do sinal de controle.

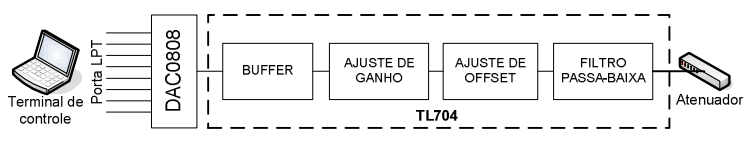

Fig.4. Bloco de controle

O atenuador recebe o sinal RF (Rádio Freqüência) de um AP (Access Point) que está confinado em uma caixa blindada, como ilustrado na Figura 5. De acordo com o fenômeno que será emulado (Rayleigh), dado que o valor de $\alpha=2$, o atenuador atua no envelope do sinal, sendo conduzido por um cabo coaxial até o segundo computador, onde há uma placa 802-PCMCIA. Uma única ligação VoIP é mantida entre o PC1 e o PC2 através do softphone X-Lite. Para a captura de informações, tais como jitter, Fator R e MOS correspondente foram utilizados o software Optiview Protocol Expert Education, e para medir a intensidade de sinal o software NetStumbler. Os testes foram repetidos para dois codificadores de voz: G711 e GSM, sendo analisados os desempenhos em relação à qualidade subjetiva (MOS), em relação ao fator $\mathrm{R}$ (Modelo $\mathrm{E}$ ), perda de pacotes, atraso e jitter de pacotes RTP (Real-Time Transport Protocol).

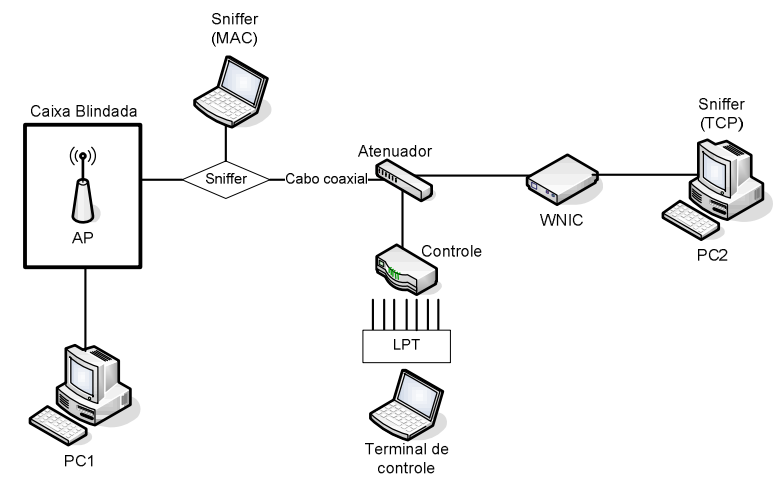

Fig.5. Bancada de teste [11]

\section{RESULTADOS}

Baseado no cenário de testes e utilizando as medidas obtidas através do robô, foram feitos experimentos que emulam o movimento de uma pessoa com velocidade constante envolta de um AP, sendo modificando apenas a severidade do ambiente através dos valores de $\beta$. e o codec utilizado.

A Figura 6 ilustra o sinal medido pelo software NetStumbler, indicando a variação da intensidade do sinal. $\mathrm{Na}$ Figura 6 o intervalo 01, há uma ligação VoIP utilizando o codec G711 PCM onde há um sinal flat fading com um $\beta=$ 1,34. No intervalo 02 tanto a ligação VoIP quanto o efeito na rede são encerrados, durante o intervalo 03 temos novamente o sinal obtido pelo mesmo $\beta$, porém o codec utilizado é o GSM.

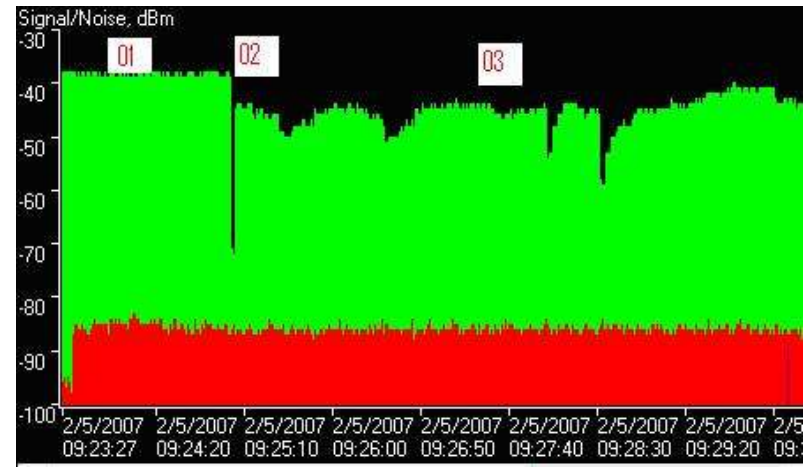

Fig.6. Variação do sinal medido pelo NetStumbler

A Figura 7 ilustra no intervalo 02 uma ligação VoIP com GSM onde o sinal é flat fading utilizando um $\beta=1,5$. Comparando o intervalo 03 da Figura 6 com o intervalo 02 da Figura 7 , nota-se que para um mesmo codec quanto maior o valor de $\beta$, maior é a variação da intensidade do sinal recebido. 


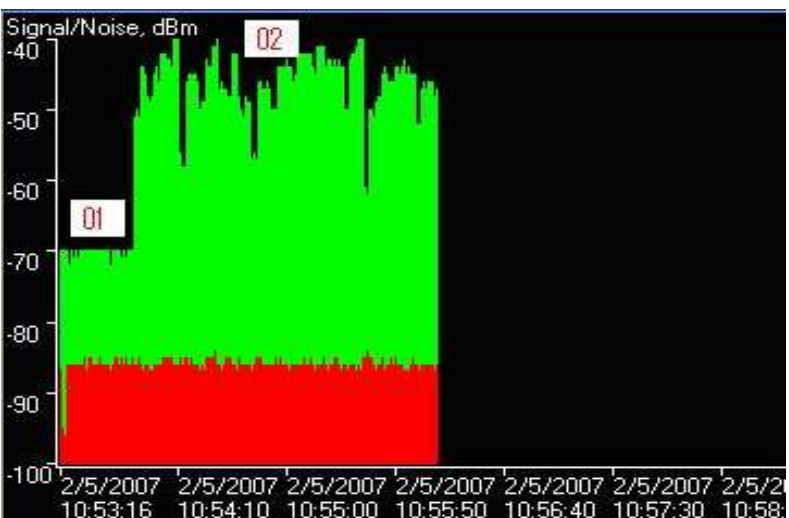

Fig.7. Variação do sinal medido pelo NetStumbler

Outro ponto importante a ser analisado foi a correlação da severidade do meio com a qualidade de voz quando utilizamos os dois codecs.

A Tabela IV apresenta os valores do Fator R, MOS e jitter de acordo com o $\beta$. Observa-se que para ambientes instáveis o G711 apresentou maior qualidade, uma vez que são transmitidos mais quadros por pacote, porém verifica-se que o codificador apresentou maior queda dos valores de MOS e do Fator-R, se comparado ao GSM.

Outro parâmetro analisado foi o jitter, ele aumentou conforme a severidade do ambiente, tanto para o codec G711, quanto para o para o GSM, conforme ilustrado na Tabela IV.

Tabela IV. Valores de jitter em função do $\beta$ e do codec utilizado

\begin{tabular}{|c|c|c|c|c|}
\hline $\begin{array}{c}\text { Codificador de } \\
\text { Voz }\end{array}$ & $\begin{array}{c}\text { Valores } \\
\text { de } \beta\end{array}$ & $\begin{array}{c}\text { Jitter } \\
\text { Máximo } \\
(\mathrm{ms})\end{array}$ & Fator- & MOS \\
\hline G.711 & 1,26 & 17,82 & 92 & 4.20 \\
\hline G.711 & 1,34 & 18,07 & 92 & 4.20 \\
\hline G.711 & 1,5 & 22,93 & 70 & 3.53 \\
\hline GSM & 1,26 & 18,45 & 66 & 3.21 \\
\hline GSM & 1,34 & 18,34 & 55 & 3.0 \\
\hline GSM & 1,5 & 23,95 & 66 & 3.21 \\
\hline
\end{tabular}

Os resultados evidenciam que o desempenho do codec G711 é superior ao codec GSM quando há instabilidade da rede. O codificador envia maior quantidade de pacotes, ocupa maior banda, porém tanto a qualidade subjetiva da voz (MOS) quanto a objetiva (Fator-R) são melhores do que os valores apresentados pelo codec GSM.

\section{CONCLUSÕES}

A investigação dos efeitos de degradação de uma WLAN, correlacionados à qualidade de voz, ao desempenho do codec, assim como aos valores de jitter, delay e perdas de pacotes, são resultados importantes, pois representam o comportamento do $\mathrm{VoWiFi}$, ou seja, comunicação de voz utilizando redes WLAN em cenários reais. As medidas realizadas por um robô para caracterização do ambiente foram utilizadas para a emulação do canal, e indicaram que a distribuição de Weibull apresenta um grau de liberdade maior para representar os fenômenos de fast flat fading de um canal indoor.

Além disso, a emulação de um ambiente que represente os cenários reais revelou que o codec G711a apresentou melhor qualidade de voz para este ambiente se comparado com o codec GSM. Portanto o codec que utiliza PCM embora ocupe mais banda e conseqüentemente permite menos usuários seria mais adequado para ambientes onde há variação de intensidade de sinal para o receptor que utiliza uma ligação VoIP.

\section{AGRADECIMENTOS}

Agradecimento especial ao Laboratório de Pesquisa em Sistemas Rádio (LPSiRa) da PUC - Campinas financiado pela FINEP, onde foram feitos os testes de VoIP

Agradecimento ao Laboratório WCN (Wireless Compentence Network) mantido pela Intel na UNICAMP por ceder parte dos equipamentos.

Agradecimento ao aluno Raphael Montali pela colaboração na análise estatística.

\section{REFERÊNCIAS}

[1] VRIENDT, Johan De. , ET AL. Mobile Network Evolution: A REVOLUTION ON THE Move. IEEE COMMUNICATIONS MAGAZINE, ABR. 2002.

[2] LOUREIRO, ANTONIO A. ET AL. COMUNICAÇ̃̃o SEM FIO E Computação Móvel: TeCnologias, Desafios e Oportunidades. IN: CONGRESSO DA SOCIEDADE BRASILEIRA DE COMPUTAÇÃO, CAMPINAS, SÃo PAULO, AGO. 2003.

[3] WANG, Wei ; LIEW, Soung Chang ; LI, O. K. Solutions to Performance Problems in VoIP OVer a 802.11 Wireless LAN. IEEE TRANSACTION ON VEHICULAR TECHNOLOGY, V.54, N.1, JAN. 2005.

[4] COLCHER, SÉRgIO ET AL, VOIP: VOZ SOBRE IP. RiO DE JANEIRO: EDITORA CAMPUS, JAN. 2005. 288P.

[5] HERSENT, OLIVER; GURLE, DAVID; PIERRE, JEAN P. TELEFONIA IP: COMUNICAÇÃO MULTIMIDIA BASEADA EM PACOTES. SÃo PAULO: ADDISON WESLEY, 2002.451P.

[6] ITU-T RECOMMENDATION P.800, "MethODS FOR SUBJECTIVE DETERMINATION OF TRANSMISSION QUALITY", 1996

[7] ITU -T RECOMENDAÇ̃̃O G.107: THE E - MODEL, A COMPUTATIONAL MODEL FOR USE IN TRANSMISSION PLANNING: ITU, 12/98. DEFINITION OF CATEGORIES OF SPEECH TRANSMISSION QUALITY. GENEVA, 1999

[8] ITU -T RecomendaÇão G.109: Definition of CATEgories OF SPEECH TRANSMISSION QUALITY. GENEVA, 1999.

[9] RAPPAPORT, THEODORE S. WIRELESS COMMUNICATIONS : PRINCIPLES AND PRACTICE. NEW JeRSEY: PRENTICE-Hall, 1996. P.69 -138

[10] Belloni, Fábio. Fading Models. In: Postgraduate Course in Radio Communications, Signal Processing Laboratory, HUT, OUT. 2004.

[11] GOES, A.; BRANQUINHO, O. C; REGGIANI, N. EMULAÇ̃̃o DE FLAT FADING PARA TESTE DE REDES WLAN EM 2,4 GHz. IN: MOMAG 2006, 2006, BELO HORIZONTE. MOMAG 2006. 